\title{
Uma visão antropológica da aplicação de questionários na pesquisa em educação
}

\section{An anthropological view of the application of questionnaires in educational research}

\author{
Alice Pereira Xavier ${ }^{1}$
}

\begin{abstract}
RESUMO
No presente estudo alguns conceitos antropológicos - ideia de vocabulário nativo, inteligibilidade e aproximação do outro - e sociológicos são acionados como estratégia para a ressignificação da aplicação de questionários, levando a considerá-la como instância de processos sociais complexos que produzem opinião. A análise das reações e atuações dos atores escolares no momento de aplicação dos questionários é considerada como uma possibilidade para a interpretação da diversidade de características materiais, das disposições e ações individuais, fundamentando a leitura dos dados quantitativos para além das explanações estatísticas. Durante a descrição deste tipo de atividade, pôde-se dimensionar a relação entre as exceções e a regularidade de comportamentos, ampliando o olhar para o futuro trabalho de observação do campo, para os mecanismos de identificação e interação com os pesquisadores e desta etapa como espaço para a reflexão de aspectos da experiência escolar. Recomenda-se, enquanto instrumento de ampliação para a abordagem quantitativa, que o conjunto de impressões sobre a aplicação de questionários na pesquisa educacional deva ser contabilizado na análise das frequências, compondo a interpretação dos resultados de pesquisa.

Palavras-chave: instrumentos de pesquisa; aplicação de questionário; pesquisa quantitativa; pesquisa em educação.
\end{abstract}

\footnotetext{
ABSTRACT

In this study, some anthropological concepts - the idea of native vocabulary, understanding and approach to the other - and sociological concepts are triggered as a strategy to reframe the application of questionnaires, consi-

${ }^{1}$ Doutoranda em Ciências Humanas, com ênfase em Educação pela Pontifícia Universidade Católica do Rio de Janeiro (PUC/RJ) Mestre em Educação Brasileira (PUC/RJ) e pesquisadora associada ao Grupo de Estudos em Sociologia da Educação (SOCED) da PUC/RJ, Brasil.
} 
dering it as an instance of complex social processes which generate opinion. The analysis of the reactions and actions of the school actors during the application of questionnaires is considered as a possibility for the interpretation of the diversity of characteristics of the materials, individual actions and dispositions, grounding the analysis of the quantitative data beyond the statistical explanations. During the description of this type of activity, it was possible to scale the relation between the exceptions and the behavior regularity, extending the look to the future work of field observation and the mechanisms for identification and interaction with the researchers, and to this step as a space for reflection on aspects of school experiences. As a tool in the expansion to the quantitative approach, it is recommended that the set of views on the use of questionnaires in educational research is accounted in the frequency analysis, being a part of the interpretation of the research results.

Keywords: research instruments; questionnaire application; quantitative research; educational research.

\section{Uma visão antropológica da aplicação de questionários na pesquisa em educação}

Enquanto uma etapa concreta das atividades de pesquisa, a aplicação de questionários tende a se constituir em um trabalho de pouca reflexão. Além da observação de como os itens se comportam, se são de difícil compreensão ou não, pouco se observa sobre o comportamento dos respondentes, suas reações, oralizadas ou não, em relação ao instrumento e ao formato da aplicação.

Algumas análises que se empenharam em problematizar o desempenho de instrumentos quantitativos para além da dicotomia qualitativo-quantitativo e da denúncia da insuficiência dos questionários na obtenção de dados subjetivos nos auxiliaram a analisar atividades de aplicação: Bourdieu (1983), Nash (2002) e Collins (2000).

Bourdieu (1983, p. 174) chama atenção para alguns aspectos de funcionamento das pesquisas de opinião - que ultrapassam a tradicional ênfase no rigor metodológico, na formulação e na aplicação de instrumentos de pesquisa - e que podem ser ampliadas para a reflexão sobre a produção e a análise de pesquisas quantitativas em educação².

${ }^{2} \mathrm{O}$ autor problematiza alguns aspectos na produção de grandes enquetes, tais como o conjunto de alternativas oferecidas, que pode vir a reduzir as opções possíveis ou mesmo induzir o respondente a determinadas opções, além da forma equivocada de interpretações destas opiniões enquanto representação de uma totalidade ou produção de uma falsa opinião média. 
Os aspectos relativos à apuração dos dados neste tipo de pesquisa devem ser levados em consideração. As taxas de não resposta, por exemplo, refletem na análise e devem ser consideradas como mais que simples ausências de opinião. É neste sentido que Bourdieu questiona a existência da opinião pública. A depender dos contextos em que se dão as aplicações, as características de gênero, nível de escolaridade, situações de conflito político ou ético irão influenciar e determinar respostas. A variação das percepções é produzida a partir de um ethos de classe ou ética de classe, que pode levar a interpretações mais ou menos moralistas ou mais ou menos estéticas, por exemplo, de acordo com a posição social das pessoas.

A complexidade dos contextos de produção de opinião requer a construção de uma estrutura com modelos que se assemelhem à complexidade dos processos sociais (NASH, 2002). Esta tarefa é um desafio para a pesquisa em sociologia da educação. Quando não se atenta para esta complexidade, as pesquisas quantitativas produzem análises reducionistas ou equivocadas que, com base em explanações estatísticas ou em teorias inadequadas, não conseguem dar conta dos processos sociais. Um caminho para enfrentar este desafio é a construção de uma narrativa explicativa do processo social articulada à pesquisa quantitativa - um modelo aplicável structure-disposition-practice model, como proposto por Nash (2002, p. 397) - para dar conta da diversidade de características materiais, das disposições e ações individuais, gerando uma análise de causas e consequências dos processos sociais.

É dentro desta perspectiva, enriquecida pelos mecanismos da observação etnográfica que iniciamos a observação e análise dos comportamentos de alunos e professores durante a aplicação de questionários.

$\mathrm{Na}$ formulação de questionários em que se produz uma pré-testagem das questões, as considerações sobre as ações dos respondentes pode ser ínfima, tendo em vista que já se captou, em grande parte, a validade dos itens. Os relatórios de aplicação que devem ser preenchidos durante ou logo após esta atividade objetivam reunir dados essenciais sobre o clima da turma durante a aplicação, número de alunos presentes e faltosos, duração, itens nos quais os alunos apresentem dificuldades para responder, entre outros. A produção destes dados, ainda assim, pode não possibilitar, pelo espaço disponível ou pela forma de abordagem dos tópicos, dimensionar nem problematizar os comportamentos dos respondentes durante a aplicação.

Estas não são as únicas dificuldades na realização deste tipo de observação. Ocorre que na aplicação de questionários não se tem a intenção de observar aquela atividade enquanto um acontecimento representativo ou uma situação em que os respondentes protagonizam algo a mais que o simples preenchimento de alternativas. As considerações formuladas, quando não são muito gerais ( $O s$ 
alunos reagiram bem; O clima estava calmo, A turma era agitada), podem ser muito pontuais e não contextualizar uma dúvida ou omissão: Os alunos não sabiam apontar o nível de escolaridade dos pais ou A maioria dos professores deixou em branco o item de análise da direção.

Com isso queremos chamar a atenção para uma série de reações dos respondentes (alunos e professores) que, em si, podem oferecer referências para a análise de questões da pesquisa educacional. Estas referências ou informações podem servir posteriormente para a análise de muitos itens do questionário, sugerindo contradições e evitando equívocos nas interpretações destes dados. Ainda que a observação e a sistematização dos comportamentos observados possam vir a não auxiliar na interpretação de determinado item, a reunião destes indícios pode se constituir em uma fonte diversificada para a observação do campo e para o dimensionamento das entrevistas.

Este exercício foi viável a partir de um olhar antropológico. A discussão de algumas categorias centrais para esta abordagem influenciou nossa percepção sobre o ambiente escolar, os alunos e os professores, durante a aplicação dos questionários. Entre as categorias antropológicas: os conceitos de nativo e de alteridade e vocabulário nativo, além dos instrumentos da pesquisa etnográfica (aproximação e distanciamento e familiaridade e distanciamento) nos direcionaram e sensibilizaram para a análise de alguns comportamentos minimizados, até então, em outras experiências de pesquisa.

Este trabalho não deve ser denominado, no entanto, de uma etnografia da aplicação de questionários, pois o tempo de inserção nas escolas não permitiu um trabalho desta natureza. Procuraremos analisar o momento da aplicação como uma situação social de pesquisa, representativa da inserção da pesquisa educacional nas escolas e da relação entre pesquisadores e pesquisados.

Neste trabalho, iremos enumerar e analisar apenas os comportamentos de alunos e professores, trazendo excepcionalmente para a análise outros atores escolares. Estas situações puderam ser enriquecidas com outras observações de pesquisadores que participaram da aplicação e que discutiram suas impressões coletivamente. Estes comportamentos observados serão trazidos à reflexão, na medida em que apresentarem semelhanças ou relações com os fatos que observamos.

A análise de uma situação social - extended-case method (GLUCKMAN, 1987), também denominado análise situacional, refere-se à coleta de um tipo especial de informações detalhadas (VELSEN, 1987, p. 345). Este método, segundo Velsen, influencia não somente a perspectiva de observação dos dados, mas sua análise, que incorpora o conflito como parte constituinte, normal e previsível do processo social. O método, nesta perspectiva, permite estudar as opções realizadas pelos indivíduos em uma determinada situação, bem como a variedade e a regularidade dos comportamentos protagonizados. 
O contato com esta orientação metodológica - análise situacional - ocorreu em meio ao processo de aplicação dos questionários, permitindo uma espécie de modelagem das nossas observações. Isso significa dizer que houve mudança na percepção do ambiente da aplicação e na observação do comportamento dos alunos e professores nesta atividade. A atenção passou a se voltar para detalhes mínimos das falas dos participantes no momento da introdução da aplicação. Passamos a circular mais entre as carteiras, acompanhando demonstrações de hesitação, dificuldades de compreensão, perguntas realizadas e comportamentos durante o preenchimento. Além disso, procuramos exercer atenção especial ao nosso próprio comportamento na interação com alunos e professores.

O método da análise situacional se desenvolve com a antropologia, buscando romper com uma perspectiva estruturalista. Esta perspectiva buscava regularidades e explicações referenciais gerais para os arranjos e sistemas sociais, abstraindo de suas análises os processos sociais, as relações e os comportamentos dos indivíduos. Para a escola estruturalista, as relações de parentesco, por exemplo, eram analisadas sob a ótica do status do indivíduo, que, por sua vez, presumia uma posição genealógica precisa. Neste tipo de análise, as possíveis variações parentais, os conflitos e as escolhas não eram contemplados, podendo se presumir, ainda, que todos os comportamentos observados seriam determinados apenas pelas relações de parentesco.

As etnografias baseadas nesta perspectiva davam ênfase à uniformidade dos dados, destacando pontualmente as exceções, de forma análoga como a simples interpretação das frequências numéricas de dados quantitativos pode nos impor. Podemos dimensionar a relação entre as exceções e a regularidade dos dados a partir de um exemplo do nosso questionário. $\mathrm{O}$ item sobre a cor $^{3}$ suscitou uma série de comportamentos, que foram diferentes na escola pública e na escola particular, se diferenciando também entre alunos e professores. Na escola pública, nas duas turmas em que estivemos, os alunos demonstraram se sentir confusos na definição da própria cor. Perguntavam uns aos outros qual era a sua cor e suas escolhas mais difíceis estavam associadas à definição entre a cor preta ou parda e branca ou parda. Alguns alunos nos pediram ajuda, perguntando qual era a cor que tinham. Na escola privada, semelhante reação foi confirmada e ampliada através da descrição de outros integrantes da pesquisa. Alguns alunos problematizaram em voz alta se sua cor era branca ou parda. Em outras escolas particulares, no entanto, os comportamentos foram permeados de brincadeiras e ironia, chegando a influenciar algumas respostas, como no caso de um aluno fenotipicamente branco que marcou a opção de cor preta.

${ }^{3}$ No questionário, o item fazia parte do último bloco e foi apresentado da seguinte forma: Como você classificaria sua cor, segundo as categorias usadas pelo IBGE? As opções oferecidas foram: Branca. Parda, Indigena, Preta; Oriental. 
Tais incidências de conflito que determinaram as opções escolhidas pelos alunos não são identificáveis durante a análise dos questionários. Apesar de observarmos muitas tomadas de posição, os comportamentos de conflito também levaram alguns poucos alunos a se absterem, numa tentativa talvez de demonstrar que não tinham uma opinião formada em relação à própria cor. Uma leitura desavisada deste item, somada à constatação mecânica de respostas válidas, poderia produzir frequências e, por sua vez, interpretações com base em percentuais amplamente equivocados.

Mas o conflito em relação à cor foi apenas um exemplo de uma série de comportamentos protagonizados por alunos e professores durante a aplicação dos questionários.

$\mathrm{Na}$ escola pública, o primeiro contato foi com os professores. Esta escola municipal fica situada no bairro de Bonsucesso, bem próxima a uma das maiores avenidas da cidade, ligando o extremo oeste ao centro do Rio de Janeiro. $\mathrm{O}$ bairro fica em uma área que comporta um grande complexo de favelas. A escola possui fácil acesso, estando próxima à área comercial. Quando chegamos à escola, fomos muito bem recebidas pela coordenadora pedagógica, que nos direcionou para a sala da direção. Lá, ofereceu um lugar para nossas bolsas e nos apresentou a alguns funcionários que estavam trabalhando. Em seguida, a diretora adjunta foi conosco para a sala dos professores, que estavam no intervalo de uma reunião e faziam um lanche. A diretora sugeriu que participássemos deste intervalo com os professores antes de iniciar a aplicação. Os professores também foram muito receptivos, pedindo que ficássemos à vontade. Pareciam estar orgulhosos e curiosos com a presença de pesquisadores na escola. A aplicação foi em uma espécie de sala de leitura/recursos, com livros, computadores, jogos e outros materiais. Neste espaço, havia um grande cartaz com alguns resultados obtidos pela escola: nota na Prova Brasil e IDEB ${ }^{4}$ dos anos de 2005 a 2007. Cabe destacar que todos os valores alcançados pela escola são maiores que as médias nacionais.

Antes do intervalo, os professores se reuniram nesta mesma sala, onde cadeiras estavam dispostas em um grande círculo. Na mesma disposição ocorreu a aplicação, fizemos uma apresentação formal da pesquisa e de nossos objetivos na investigação de escolas que mantêm um ensino de qualidade. Acredito que tenhamos lançado mão de certo argumento de autoridade neste momento, men-

${ }^{4}$ Prova Brasil - Avaliação do Rendimento Escolar é um exame nacional que avalia as habilidades em Língua Portuguesa e Matemática de alunos de $4^{\mathrm{a}}$ à $8^{\mathrm{a}}$ séries do ensino fundamental (Fonte: < http://provabrasil.inep.gov.br/index>.) e IDEB - Índice de Desenvolvimento da Educação Básica - é a sigla do cálculo feito a partir da taxa de rendimento escolar (aprovação) e das médias de desempenho nos exames padronizados nacionais (Fonte: <http://portalideb.inep.gov.br/>). 
cionando que o grupo de pesquisa tinha dez anos de existência e que, desde então, vinha publicando diversos trabalhos sobre a produção da qualidade do ensino. Uma colega da pesquisa se disponibilizou em retirar dúvidas e coletar sugestões. Procuramos deixar os professores à vontade para fazer sugestões e críticas ao questionário. A última folha do instrumento tinha um espaço para este fim.

A maioria dos professores levou em média vinte minutos para responder. Duração que havíamos calculado para a leitura e resposta de oito páginas, com questões formuladas com cinco, oito ou mais itens, sem contar com as questões abertas e aquelas destinadas às sugestões. Ocorre que alguns professores preencheram rapidamente os questionários, alguns levaram dez e até oito minutos. Acreditamos que este comportamento, associado ao fato de estes não terem feito nenhuma pergunta ou comentário, pode estar relacionado a um desejo de demonstrar familiaridade com o instrumento. Ao avaliar o clima e a recepção, a ideia dos professores não oferecerem muito crédito a pesquisas deste tipo ou, ainda, de desejarem finalizar logo aquele momento para fazer qualquer outra coisa, são hipóteses menos prováveis para a velocidade na execução da atividade.

O clima durante a aplicação era bastante agradável, todos pareciam tentar descontrair o ambiente. Os professores brincaram conosco, fingindo se comportarem como alunos, insinuando dúvidas e requisitando nossa presença. De maneira geral, as dúvidas foram poucas. Um professor nos perguntou se deveria incluir entre as escolas que trabalha uma faculdade que leciona e se esta seria contada como mais uma escola na análise do questionário. Pedimos ao professor incluísse a faculdade.

Um pequeno grupo de três professores levou mais tempo que os demais para responder, chegando a permanecer trinta minutos com o questionário. Estes mesmos professores iniciaram uma conversa sobre a formação na universidade que representávamos. Um professor de Física mencionou o nome de um antigo docente desta instituição que conhecera, mas que já estava aposentado; disse também que gostaria de fazer o mestrado, mas que não fazia porque o Departamento de Educação não trabalhava com a linha de pesquisa pela qual tinha interesse. Este mesmo professor se despediu, nos desejando sorte no trabalho. Outra professora (de Educação Artística) nos perguntou sobre as formas de ingresso no mestrado, se o curso era pago ou não, entre outras questões. Comentário semelhante a este foi observado durante a aplicação para alunos em uma das escolas privadas de nossa amostra, no qual a professora de Biologia havia demonstrado interesse em estudar conosco.

Vale destacar que em nenhum momento os professores nos fizeram perguntas sobre os itens do questionário, não teceram comentários e nem sugestões, mesmo quando os estimulávamos para isso. Também aparentaram indiferença em relação aos objetivos da pesquisa. Essa atitude causou certo estranhamento, 
por ser bastante diferente de outros ambientes de aplicação com professores em instituições públicas.

A aplicação do questionário aos alunos foi observada em dois diferentes contextos, em uma escola pública e em uma particular. ${ }^{5}$ A primeira interação com os alunos foi em uma escola particular bilíngue, situada na área central da cidade.

Cinco pesquisadoras do nosso grupo se dirigiram a esta escola para aplicar o questionário a cinco turmas do período da manhã. Na nossa chegada, fomos encaminhadas para a sala da coordenação, onde foi oferecido um café. O clima era de certa formalidade. Fomos recepcionadas por um coordenador, portando um mapa com os horários e atividades das turmas, e que nos fez uma série de orientações sobre os horários reservados previamente para nossa inserção nas turmas e sobre o intervalo após o período destinado à aplicação. Este coordenador nos encaminhou a cada sala, nos apresentando aos professores que estavam nas turmas. Estes permaneceram nas salas para acompanhar a aplicação. Durante o período que passamos na escola, o clima foi de manutenção da organização e da disciplina.

$\mathrm{Na}$ aplicação com os alunos, foram observados comportamentos de outra ordem, relacionados a diferentes reações e respostas aos itens do questionário. A professora e a turma nos receberam bem, havia uma agitação natural, expressando curiosidade sobre a atividade. Fizemos uma apresentação pessoal (formação acadêmica), falamos um pouco sobre a pesquisa e de algumas escolas particulares que já haviam sido investigadas. Também explicamos que os dados seriam tratados estatisticamente e que seus nomes seriam mantidos em anonimato. Os alunos não fizeram perguntas.

Durante o preenchimento do questionário, algumas dúvidas surgiram e os alunos nos chamavam em suas carteiras para auxiliá-los. Uma das primeiras dúvidas referia-se à palavra entediado, que fazia parte de um item escalar sobre senso de pertencimento e aprendizagens proporcionadas pela escola. Um aluno pediu para explicar o sentido desta palavra. Traduzimos esta sensação para o aluno, enfatizando a angústia que sentimos quando não temos nada para fazer ou quando fazemos algo de que não gostamos. $\mathrm{O}$ aluno balançou a cabeça e disse não se sentir desta forma o tempo todo na escola. Pudemos presenciar a mesma dúvida na escola pública posteriormente e outros integrantes da pesquisa também fizeram comentários semelhantes.

Não tivemos a oportunidade de aprofundar as possíveis causas desta dúvida. $\mathrm{O}$ usual conhecimento da palavra em questão nos leva a acreditar que as

\footnotetext{
${ }^{5}$ Incluiremos comentários sobre a aplicação na escola pública, na medida em que surgirem reações e comportamentos comuns; no entanto, o objetivo aqui não é o de realizar uma comparação entre as escolas, mas o de descrever aspectos de uma mesma situação de pesquisa.
} 
reações dos alunos podem não estar baseadas no sentido do termo. Por outro lado, percebemos que neste item escalar alguns alunos pulavam linhas, deixando-as em branco. Observamos certa demora e hesitação para completar as alternativas nas duas escolas. Posteriormente, ao realizarmos uma leitura coletiva dos questionários com o grupo, foi comentado que havia uma série de ausências e pulos neste item, o que nos levou a inferir que a compreensão do item era baixa ou, ainda, que teria ocorrido desinteresse dos alunos em responder.

Outro aspecto da escola particular a ser destacado refere-se ao conhecimento em língua estrangeira. Neste item, pedimos aos alunos que classificassem seu nível de conhecimento em inglês, francês e espanhol. Estando em uma escola bilíngue alemã, os alunos reagiram, questionando a ausência desta língua entre os itens. A nossa reação foi a de, mesmo sem o consentimento do grupo, pedir aos alunos que incluíssem a língua no item e que a avaliassem da mesma forma. Este acontecimento gerou comportamentos diferentes entre os alunos: alguns acataram meu pedido, outros deixaram o item inteiro em branco e outros, ainda, responderam apenas seu conhecimento em alemão ou inglês, ignorando o francês e o espanhol. ${ }^{6}$ Relatos similares foram feitos sobre outras turmas.

Uma dúvida dos alunos, que pôde também ser observada em outras unidades privadas, foi o desconhecimento do nível de escolaridade dos pais. $\mathrm{O}$ item apresentava as recentes e antigas nomenclaturas dos diferentes níveis de ensino. Observamos dois tipos de reação em relação ao item: alguns alunos (poucos) pediram orientações e uma grande parcela deixou o item em branco. Não sabemos especificar ao certo se os alunos não reconheceram estas nomenclaturas ou se não sabiam o grau de instrução dos pais. Este é um aspecto a ser investigado em conjunto com outros dados sobre a relação entre os pais e alunos. ${ }^{7}$

$\mathrm{Na}$ escola pública, participamos da aplicação em duas turmas. De forma semelhante à outra escola, fizemos nossa apresentação pessoal e falamos da pesquisa. Nesta introdução, ouvimos alguns comentários dos alunos, perguntando para que serviria uma pesquisa na escola e o que aconteceria depois com os questionários. Procuramos responder às perguntas dos alunos, explicando o que é uma pesquisa e como pretendíamos tratar os dados. ${ }^{8}$

${ }^{6} \mathrm{Na}$ escola pública municipal, a mesma pergunta sobre línguas apresentou muitas questões em branco ou com pulos entre os itens. Não observamos qualquer reação dos alunos que possa nos auxiliar na compreensão desta ausência. A inferência, neste sentido, foi de que o insuficiente conhecimento em línguas estrangeiras tenha levado alguns a não responder.

${ }^{7} \mathrm{Na}$ escola pública, os alunos não fizeram perguntas em relação ao item, deixando muitos em branco.

${ }^{8}$ É difícil definir para os alunos alguns conceitos sobre a pesquisa. Tentamos associar a investigação nas escolas com a ideia que os mesmos têm sobre pesquisa científica, geralmente baseada nas ciências naturais ou na biologia. 
A turma ficava no segundo andar da escola, ao lado da quadra de esportes. A janela, voltada para a quadra, trazia um barulho bastante incômodo para o ambiente. Comentamos sobre o assunto com o professor, que falou que a escola estabelece um rodízio entre as turmas, no qual cada uma permanece naquela sala por um mês. Os alunos reclamaram do barulho conosco. No mais, se mostraram interessados em responder o questionário.

Quando iniciaram a leitura, os alunos começaram a fazer muitos comentários entre si. Nos momentos em que apresentavam suas dúvidas e discutiam entre si, eram desencorajados com o intuito de que suas respostas não fossem influenciadas pela de seus colegas. As carteiras eram duplas, o que facilitava a interação entre eles; assim, impedir que as respostas sofressem tal influência foi uma tarefa quase impossível. Diante dos nossos pedidos, os alunos foram apenas mais discretos e conversavam entre dentes. De qualquer forma, suas alternativas seriam enviesadas pelas conversas com seus colegas. O comportamento desta turma nos levou a ressignificar esta suposta regra, bastante comum da aplicação de questionários: Até que ponto seria válido impedir esta interação entre os alunos? Não seria mais interessante observar como determinadas respostas seriam determinadas pela relação entre pares?

Apesar de não termos conseguido identificar com precisão todos os itens do questionário que estimularam maior interação, percebemos que alguns deles geraram mais trocas entre os alunos, como o item que os pedia para citar três livros que mais gostaram de ler nos últimos dois anos, frequência de conversa entre pais e filhos, a classificação da cor (tema polêmico também em outras turmas e escolas). Para outros tantos itens, tão ou mais polêmicos quanto os citados, o comportamento geral foi o de responder sem argumentação entre os colegas.

A maioria dos alunos desta turma demorou, em média, quarenta minutos para finalizar o questionário. Alguns chegaram a levar cinquenta minutos. $\mathrm{O}$ aspecto do tempo para a resposta pode ser analisado de diferentes maneiras. $\mathrm{Na}$ segunda turma em que aplicamos o questionário na escola pública, por exemplo, houve uma demora ainda maior que na primeira e alguns alunos chegaram a levar uma hora para finalizar a atividade. Esta última aplicação aconteceu depois do intervalo de recreio, com os alunos muito agitados. O professor desta turma havia faltado e estava sendo substituído por uma professora, que era funcionária da secretaria. Nesta situação, os alunos explicitamente tentaram tomar o maior tempo possível da aula e a professora (funcionária), por sua vez, não incitou maior velocidade.

A identificação e a dificuldade em atribuir significado a algumas expressões foi outro aspecto que nos surpreendeu. Duas delas nos chamaram atenção: coordenação pedagógica e apoio escolar. Ao usarmos estas expressões para formular o questionário, concebemos uma definição que não foi compreendi- 
da pelos alunos. Estas expressões se apresentaram como termos nativos, que adquiriram significados que extrapolaram a nossa concepção no momento de formulação do questionário.

No item que fez menção à coordenação pedagógica, pedíamos aos alunos que classificassem seu relacionamento com vários atores escolares: colegas, professores, direção, funcionários e o coordenador pedagógico. Alguns alunos não conseguiram identificar a pessoa que exercia esta última função; outros, ainda, não tinham noção do que consistia este trabalho. Poucos alunos conheciam a pessoa que exercia tal função na escola e, assim, falaram para seus colegas. Esta característica foi observada particularmente na escola pública.

A expressão apoio escolar também levantou algumas dúvidas e comentários entre os alunos, no entanto, pudemos identificar causas diferentes. Neste item, pedíamos que nos indicassem se tiveram algum tipo de apoio escolar nos últimos doze meses, bem como a necessidade no uso deste apoio. Ocorre que esta expressão pode comportar diferentes significados em cada escola e representar outras definições além das que apresentamos: reforço escolar oferecido pela escola ou acesso a professor particular. Na escola pública, o apoio escolar ganhou outra ênfase, como a carga horária extraordinária oferecida em virtude de outras avaliações externas (ingresso em outras instituições de ensino), sobretudo, para estudantes com rendimento acima da média. Não seria possível conhecer esta especificidade da escola sem acompanhar o processo de aplicação dos questionários de forma mais detida.

Por meio da leitura coletiva dos questionários respondidos pelos alunos, percebemos que situação semelhante ocorreu tanto na escola pública quanto na escola particular. Em uma escola particular, outros integrantes da pesquisa chamaram atenção para a dificuldade dos alunos com outras expressões, tais como atividade extraclasse, ensino superior e pós-graduação. ${ }^{9}$

Supomos que algumas palavras poderiam ser compreendidas pelos estudantes e supomos que outras, ainda, eram de seu domínio, fazendo parte de seu vocabulário. Diante das expressões ensino superior e pós-graduação, a reação dos pesquisadores, bem como de alguns professores presentes nas turmas, foi tentar explicar o significado das mesmas.

Estas situações refletem problemas experimentados (pode-se dizer que de forma semelhante) pelos estudos antropológicos: o desconhecimento do vocabulário nativo e a falta de inteligibilidade das categorias propostas pelos pesquisadores são dificuldades comuns em uma pesquisa desta natureza. Uma situação exemplar ilustra a problemática. Laura Bohannan (1966), em seu

\footnotetext{
${ }^{9}$ Estas duas últimas expressões compõem o item sobre a escolaridade dos pais.
} 
esforço para tornar a literatura de Shakespeare inteligível aos nativos da tribo Tiv, na África Ocidental, realizou uma série de adaptações na linguagem. Para tanto, precisou reestruturar premissas e valores ligados às representações de morte, às relações familiares, à organização da comunidade, entre outros. Sua tese era a de que determinados valores e dilemas considerados universais dependem, para sua compreensão, apenas de uma tradução ou releitura contextual. A pesquisadora, para traduzir Shakespeare e torná-lo compreensível aos Tivs, precisou utilizar o vocabulário nativo. Ao compartilhar a história, termina por reinventá-la coletivamente, construindo uma modificação e ampliação daquilo que considerava enquanto sentido universal.

Mas é possível buscar os significados partilhados pelos nativos e torná-los inteligíveis? Darnton (1986) consegue realizar esta aproximação por meio da interpretação de um registro que narra o cotidiano de trabalhadores de uma gráfica, na Paris do fim da década de 1730. A partir da narrativa de um massacre de gatos realizado em protesto pelos operários, o pesquisador precisa a simbologia de alguns animais, em especial dos gatos, datando sua significação em diversas situações sociais. Darnton (1986, p. 108), com seu estudo, não somente conseguiu propor uma interpretação diferente da ênfase idílica que alguns historiadores conferem à época do início da industrialização, mas também analisar os significados sociais de uma série de comportamentos: a relação patrão-operário, a condição de vida dos trabalhadores, suas necessidades e insatisfações.

No caso da nossa pesquisa, existia um conhecimento prévio do campo (escola) e dos nativos (alunos). Nossa experiência com a formulação e aplicação de questionários anteriores nos muniu de certa confiança em relação a este campo. Acontece que, ao presumir uma regularidade no uso destas expressões, abstraímos consciente e inconscientemente as particularidades e significações próprias do campo. O necessário exercício sociológico de abrir mão das particularidades em busca das regras nestas relações sociais escolares estreitou a interpretação sobre o uso de expressões como o apoio escolar e a coordenação pedagógica, por exemplo.

Observamos que outros comportamentos dos alunos foram comuns às duas escolas. Entre estes, marcar a questão do meio, o que me pareceu a tentativa de escolha de um espaço híbrido entre as alternativas, na medida em que os itens que propusemos não deram conta da complexidade de suas experiências escolares e familiares. Além disso, os alunos inseriram comentários e sugestões sobre a pertinência de alguns itens. Incluíram, por exemplo, novas categorias para a indicação dos livros que leram ${ }^{10}$ : eu mesmo, eu sozinho, a internet, vi

${ }^{10}$ Nós construímos as seguintes categorias para a origem de indicação dos livros: escola, família e amigos. 
em um site etc. Estas proposições dos alunos nos levaram a considerar a mídia como um fator significativo que compõe a indicação de suas leituras.

Optamos pela inserção nas escolas antes de um estudo exploratório, aplicando uma espécie de termômetro (no caso, os questionários) para posteriormente aprofundar determinados aspectos da rotina escolar. A análise dos comportamentos e dos significados atribuídos durante as atividades de aplicação dos questionários trouxe uma diferente perspectiva para a investigação, possibilitando uma fundamentação diferente para a interpretação dos dados quantitativos e ampliando nosso olhar para o futuro trabalho de observação do campo.

\section{Considerações finais: a regularidade nas irregularidades}

Velsen (1987) propõe que a análise situacional oferece melhores condições de interpretação do comportamento acidental ou excepcional, sem desintegrá-lo de uma visão estrutural. Desta forma, enfatiza a importância das referências estruturais para a interpretação dos comportamentos. Tal perspectiva foi pertinente a esta análise, que pretendeu dar foco aos comportamentos dos atores escolares. Ao ilustrar as situações concretas da pesquisa e alguns problemas encontrados no campo, a ideia foi captar a variedade de comportamentos individuais de alunos e professores ao responderem o questionário.

Há certa regularidade nas irregularidades: Velsen (1987, p. 361) usa esta expressão para ilustrar outras ordens de regularidades, interpretando um sistema social em termos de normas conflitantes. Ao lançar esta perspectiva para a aplicação dos questionários, por exemplo, percebemos que alguns comportamentos acionados pelos alunos e as dificuldades de compreensão de alguns itens não podem ser interpretados mecanicamente como dúvidas fortuitas, como simples exceções. Por outro lado, alguns comportamentos até então considerados atípicos podem ser típicos no preenchimento de questionários.

Vimos que diante de determinados itens conseguimos identificar um conjunto de comportamentos mais ou menos típicos. Em outros casos, a observação de um tipo de comportamento não pôde ser generalizada para a interpretação de outros itens. No caso da definição da cor, enquanto um grupo problematizou, o outro brincou e ironizou com a situação de dúvida. Os dois tipos de comportamento influenciaram as respostas, mas de modo diferente. Seria a variação deste comportamento uma ilustração do efeito de ethos de classe (BOURDIEU, 1983)? Tais comportamentos, que podem ser comumente "superinterpretados", podem ser ressignificados sobre esta ótica de investigação e decerto merecem outros investimentos de pesquisa. 
Professores e alunos optam por um comportamento durante as atividades de pesquisa. Muitos destes comportamentos explicitam a tensão estrutural (VELSEN, 1987, p. 348) $)^{11}$ que experimentam ao responderem este instrumento de pesquisa, ao se defrontarem com questões incômodas ou ao não terem uma opinião formada sobre determinado item. Os comportamentos ilustram momentos de rearranjo, que podem adquirir diferentes significados, suscetíveis à interação e ao ambiente durante a aplicação. Acrescentamos, ainda, que as aparentes dúvidas (como a relacionada ao tédio, por exemplo) e as inquietações proporcionadas pelo momento da aplicação podem funcionar como oportunidades para a reflexão sobre aspectos da experiência escolar ainda não problematizados.

Um conjunto de comportamentos me levou a pensar que professores e funcionários não estavam acostumados à presença de pesquisadores na escola. As tentativas de aproximação do outro e a criação de mecanismos de identificação com os pesquisadores podem ser considerados comuns durante interações deste tipo? Em que medida? A forma de inserção da nossa pesquisa parecia estar aliada aos objetivos da escola municipal, sendo vista como uma oportunidade de manutenção da boa avaliação. A recepção explicitava a mensagem de que estavam aptos a serem avaliados. Havia um clima de bem-estar e de trabalho bem feito, professores e funcionários demonstravam segurança.

Por fim, cabe a ressalva de que os comportamentos observados não devem induzir à invalidação das referências estruturais ou à total desconsideração dos que foram enviesados ou não compreendidos. Enquanto instrumento de ampliação para a abordagem quantitativa, o conjunto de impressões sobre a aplicação deve ser contabilizado na análise das frequências, compondo a interpretação dos resultados de pesquisa.

\section{REFERÊNCIAS}

BOURDIEU, P. A opinião pública não existe. In: Questões de Sociologia. Trad. de Jeni Vaitsman. Rio de Janeiro: Marco Zero, 1983, p. 173-182.

BOHANNAN, L. Shakespeare in the bush. In: Natural History, ago./set. 1966. Disponível em: $<$ http://www.naturalhistorymag.com/picks-from-the-past/12476/shakespeare-in-the-bush>. Acesso em: 12/11/2009.

${ }^{11}$ Expressão que caracteriza o defrontar do indivíduo na escolha entre padrões alternativos. 
COLLINS, R. Situational Stratification: a micro-macro theory of inequality. In: Sociological Theory, San Francisco, American Sociological Association, v. 18, n. 1, p. 17-43, mar. 2000.

DARNTON, R. O grande massacre de gatos e outros episódios da história cultural francesa. Trad. de Sônia Coutinho. Rio de Janeiro: Graal, 1986.

GLUCKMAN, M. Análise de uma situação social na Zululândia moderna. In: FELDMAN-BIANCO, B. (Org.). Antropologia das sociedades contemporâneas - métodos. São Paulo: Global Universitária, 1987, p. 227-267.

IDEB - Índice de Desenvolvimento da Educação Básica. Disponível em: <http://portalideb.inep.gov.br/br>. Acesso em: 10/12/2009.

NASH, R. Numbers and narratives: further reflections in the sociology of Education. British Journal of Sociology of Education, v. 23, n. 3, p. 397-412, 2002.

PROVA BRASIL - Avaliação do Rendimento Escolar. Disponível em: <http://prova. brasil.inep.gov.br/index $>$. Acesso em 10/12/2009.

VELSEN, J. V. A análise situacional e o método de estudo de caso detalhado. In: FELDMAN-BIANCO, B. (Org.). Antropologia das sociedades contemporâneas - métodos. São Paulo: Global Universitária, 1987, p. 345-374.

Texto recebido em 20 de janeiro de 2010.

Texto aprovado em 04 de agosto de 2010. 